\title{
MIGRATION AND FERTILITY IN THAILAND, 1960-1970
}

\author{
Sidney Goldstein \\ Population Studies and Training Centre \\ Brown University, Providence, Rhode Island, U.S.A.
}

Résumé - Toute estimation complète des niveaux et des taux changeants d'urbanisation dans les pays moins développés doit comprendre une évaluation des rôles des migrations et de la fécondité, portant une attention particulière à la fécondité comparative des femmes non-migrantes et des femmes migrantes dans les communes urbaines aussi bien que dans les communes rurales. La recherche en question profite des données enregistrées des recensements de 1960 et surtout de 1970 de la Thaillande pour analyser le comportement procréateur des émigrants à Bankok en rapport avec celui des femmes migrantes dans des communes urbaines plus petites et dans des communes rurales. On a aussi comparé les femmes migrantes aux femmes non-migrantes des catégories de résidence respectives et on a tenu compte des effets de la date récente de la migration et de l'origine du mouvement sur la mesure dans laquelle les émigrants assimilent le comportement procréateur des non-migrantes au lieu de destination. On a déterminé la fécondité en termes du nombre total des enfants déjà nés. Les conclusions indiquent presque pas de différence entre les niveaux de fécondité des émigrants à vie et ceux des indigènes au lieu de destination. Au contraire, la fécondité des émigrantes à cinq ans est en dessous de celle des non-émigrantes à la destination aussi bien qu'à l'origine, avec la plus basse fécondité caractérisant les femmes qui émigrent vers Bankok venant des autres communes urbaines. Les différentielles l'emportent sur les différences produites par l'état d'émigrant. Une fécondité rurale considérablement plus élevée persiste même après le contrôle de l'état d'émigrant; et la fécondité est plus élevée dans les communes urbaines plus petites qu'elle l'est à Bankok. De plus, les émigrantes d'origine urbaine ont une fécondité plus basse que celles d'origine rurale dans chaque catégorie de résidence, mais la plus basse fécondité caractérise les émigrantes d'origine urbaine à Bankok et la plus élevée les émigrantes d'origine rurale aux autres communes rurales, suggérant que les facteurs en rapport avec la sélection et l'adaptation des émigrantes ont un impact combiné sur les niveaux de fécondité.

Abstract - A full assessment of the changing levels and rates of urbanization in less-developed countries must include an evaluation of the roles of migration and fertility, with particular attention to the comparative fertility of non-migrant and migrant women in both urban and rural places. The present research takes advantage of data from sample tapes of the 1960 and especially the 1970 Censuses of Thailand to analyze the fertility behaviour of migrants to Bangkok in relation to that of migrant women in smaller urban places and in rural areas. The migrant women are also compared to the non-migrants in the respective residence categories; and account is taken of the effects of recency of migration and origin of move on the extent to which migrants assimilate the fertility behaviour of the non-migrant women at place of destination. Fertility is measured in terms of total number of children ever born. The findings indicate almost no difference between the fertility levels of lifetime migrants and those of natives at place of destination. By contrast the fertility of five-year migrants is below that of non-migrants at both destination and origin, with the lowest fertility characterizing women moving to Bangkok from other urban places. Overriding the differences by migration status are the urban-rural differentials. Considerably higher rural fertility persists even after migration status is controlled; and fertility is higher in smaller urban places than it is in Bangkok. Moreover, urban-origin migrants have lower fertility than rural-origin women in each residence category, but the lowest fertility characterizes urban-origin migrants to Bangkok and the highest rural-origin migrants to other rural locations, suggesting that factors associated with both the selection and the adjustment of migrants have joint impact on fertility levels. 
Sidney Goldstein

Key Words - migration, fertility, urbanization, Thailand

\section{Introduction}

Many of the most crucial problems that mankind will have to face and solve in the remaining decades of the twentieth century, and probably well into the twenty-first, are related not so much to the absolute size and rate of population growth, important as these are, but rather to the particular pattern of settlement and the increasing rate of growth and concentration of population in urban areas. Three interrelated situations continuing rapid overall population growth, massive increases in the size of the urban population and rising levels of urbanization, and dramatic rises in the number of big cities and in the concentration of both the total national and the urban population in such cities - present both researchers and policy makers with new challenges and opportunities. Yet, despite these developments, urbanization and population redistribution remain among the demographic phenomena about which the least is known (Goldstein and Sly, 1975).

There is a pressing need to assess the changing levels and rates of urbanization, the relation of urbanization to the ongoing economic, social, and demographic changes, and the respective roles of migration and of fertility in the urbanization process. Moreover, in any concern with the components of the urbanization process, particular attention must be given to the comparative fertility of the migrant and non-migrant women both in urban and in rural places. Numerous studies have attempted to gain insights into the possible interrelations between migration and fertility. A wide variety of conflicting evidence has been presented, as documented by the comprehensive and critical review of the literature undertaken by Zarate and Zarate (1975). Different studies have concluded that migrant fertility is higher, lower, or the same as that of non-migrants, but many of the differences in conclusion reflect differences in study design, in analytic methods, in definitions of migrants, and in the measures of fertility used. We need clarification regarding, among other matters, who the migrant is, who the urban native is, what intercultural differences may exist, what constitutes urban fertility, and what the effects of differences in urban size are before we can have a clearer assessment of the interaction between migration and fertility and their joint impact on growth rates in both urban and rural places.

In an attempt to gain additional insights into the answers to these questions, the research reported here focuses on the interrelations between migration and fertility in Thailand. Although no country is typical in a pure sense of the term, Thailand serves well as an example of a less-developed country facing the problems of a rapidly changing demographic situation: it has had among the highest population growth rates in the world as a result of plunging death rates and continuing high fertility; rural to urban migration and a rising level of urbanization have both been assuming increased importance; Bangkok qualifies as one of the most primate cities in the world; and its demographic experience and features provide sharp contrasts with those of the smaller urban places in the kingdom and especially with rural places. (For a fuller discussion of urbanization in Thailand see Goldstein, 1971b; Goldstein, 1972.)

For these reasons, the following assessment of the fertility of migrants will be comparative in character, analyzing the fertility behaviour of migrants to Bangkok in relation to that of migrant women to the smaller urban centres of Thailand and concurrently with that of the large number of migrants in rural locations. In all instances, the migrant women will be compared with the non-migrants in their respective residence categories: In doing so, account will be taken, as far as feasible, of the effect of the recency of the migration and the origin of the move, both of which may affect the extent 
to which migrants assimilate the fertility behaviour characterizing the non-migrant women at place of destination.

\section{Sources of Data}

The data used in this study come from special sample tapes from the 1960 and 1970 Censuses of Thailand. (More complete descriptions of the data available from the 1960 tape may be found in Goldstein, 1970; for 1970, see Arnold and Boonpratuang, 1976.) The 1960 data provided migration information based on a place of birth question as well as on one that ascertained place of residence five years before the Census. Both these sets defined migration as movement across provincial boundaries. (There were 71 provinces in Thailand in both 1960 and 1970.) Fertility data in the census refer to the number of children ever born to ever-married women. Cross-tabulation of these data made it possible to ascertain the number of children ever born to five-year and lifetime migrants in Thailand. Information was also available on rural-urban residence in 1960 and on major household economic activity, permitting a five-fold continuum of urban-rural status, ranging from Bangkok at the one extreme - representing the most urbanized segment of the population - to rural, agricultural households at the other end (Goldstein, 1970).

These data have several limitations for assessing interrelations between migration and fertility. Because they contain information only on total number of children ever born, it 'is not possible to distinguish between births that occurred before and after migration. A second limitation relates to the fact that data available from the 1960 Census did not include rural or urban origin of the migrants; such a limitation can be particularly serious if rural-urban differentials in fertility behaviour exist. Nonetheless, the data provide some opportunity to gain insights into the migrant-non-migrant fertility differentials and the impact of length of urban residence on the differentials. Moreover, comparison of the number of children ever born to migrants resident in urban places with the fertility of women still living in rural areas, where a majority of the migrants presumably originated, can shed some light on the selection process at point of origin.

The 1970 Census largely followed that of 1960 , both in kinds of questions asked and in the classification systems used. This makes for fairly close comparability. For 1970, fertility continued to be measured by children ever born. Migration data were available in terms of both place of birth and by duration of residence; the latter could be used to ascertain movement within the five years preceding the census to provide comparability with the 1960 data for movement involving changes in province of residence. Overcoming one of the major limitations of the 1960 data, the 1970 Census data also permit measurement of migration in terms of a change in rural and urban residence, and do so for both intra- and interprovincial movement in the five years preceding the census. As in 1960, urban residence refers to residence in one of the 119 municipal areas, and Bangkok is distinguished from the other urban places; the remainder of the population is classified as rural. No distinction is made by household economic status.

\section{Fertility and Migration, 1960}

In 1960, the relation between fertility and migration varied depending on the measure of migration used. Overall, the data based on lifetime migration failed to point to any substantial difference in fertility levels between the migrant and non-migrant women in the Thai population at place of destination (Table 1). This does not necessarily mean that migration status does not affect fertility level. A serious limitation of the place of birth data is that they do not permit determination of when migration occurred, nor is it 
Sidney Goldstein

TABLE 1. NUMBER OF CHILDREN EVER BORN PER 1,000

EVER-MARRIED WOMEN, BY MIGRATION STATUS AND URBAN-RURAL RESIDENCE, 1960

\begin{tabular}{|c|c|c|c|c|}
\hline \multirow[b]{2}{*}{ Residence } & \multicolumn{4}{|c|}{ Migration Status } \\
\hline & $\begin{array}{l}\text { Non- } \\
\text { migrants } \\
\text { (Non-stand }\end{array}$ & $\begin{array}{l}\text { Migrants } \\
\text { fardized) }\end{array}$ & $\begin{array}{c}\text { Non- } \\
\text { migrants } \\
\text { (Standardized } \\
\end{array}$ & $\begin{array}{l}\text { Migrants } \\
\text { d for Age) }\end{array}$ \\
\hline \multicolumn{5}{|c|}{ LIFETIME MIGRATION STATUS ${ }^{1}$} \\
\hline $\begin{array}{l}\text { Bangkok } \\
\text { Other urban, non-agricu1 tura1 } \\
\text { Urban, agricultura1 } \\
\text { Rura1, non-agricultura1 } \\
\text { Rura1, agricultural }\end{array}$ & $\begin{array}{l}3,310 \\
3,777 \\
4,307 \\
3,847 \\
4,361\end{array}$ & $\begin{array}{l}3,487 \\
3,845 \\
3,881 \\
3,969 \\
4,850\end{array}$ & $\begin{array}{l}3,443 \\
3,813 \\
4,113 \\
3,998 \\
4,434\end{array}$ & $\begin{array}{l}3,340 \\
3,725 \\
3,665 \\
4,039 \\
4,713\end{array}$ \\
\hline Total Kingdom & 4,255 & 4,308 & 4,339 & 4,205 \\
\hline \multicolumn{5}{|c|}{ FIVE-YEAR MIGRATION STATUS ${ }^{2}$} \\
\hline $\begin{array}{l}\text { Bangkok } \\
\text { Other urban, non-agricul tural } \\
\text { Urban, agricul tural } \\
\text { Rura1, non-agricultural } \\
\text { Rural, agricultural }\end{array}$ & $\begin{array}{l}3,517 \\
3,850 \\
4,285 \\
3,920 \\
4,424\end{array}$ & $\begin{array}{l}2,376 \\
3,175 \\
2,222 \\
3,160 \\
3,682\end{array}$ & $\begin{array}{l}3,427 \\
3,7.94 \\
4,032 \\
4,032 \\
4,468\end{array}$ & $\begin{array}{l}2,982 \\
3,485 \\
3,058 \\
3,740 \\
4,242\end{array}$ \\
\hline Total Kingdom & $4 ; 292$ & 3,284 & 4,326 & 3,878 \\
\hline
\end{tabular}

Source: Special tabulations, 1960 Thai Census.

1. Defined as a change in province of residence between birth and the time of the 1960 Census.

2. Defined as a change in province of residence between 1955 and the time of the 1960 Census.

possible to ascertain whether the children were born before or after the move. By failing to indicate migrants' duration of residence in place of destination, these data also precluded any effort to evaluate the extent to which the migrants had an opportunity to assimilate the fertility values and behaviour of the non-migrant population. Moreover, selective return migration and mortality may have affected the fertility differentials; the fertility of the migrants remaining in their place of destination may have been lower than that of other migrants who returned to rural places.

Within these limitations, then, 1960 lifetime migration status does not seem to affect fertility at place of destination. If, however, one assumes that these lifetime migrants to urban places came largely from rural origins, comparison of the fertility levels of the migrants in urban places with those of the non-migrants in the rural, agricultural category pointed to selection at place of origin or assimilation of fertility values at destination. For example, the average number of children ever born to migrant women in Bangkok is almost 25 per cent below the average for rural non-migrants; even compared to those in other urban places, lifetime migrants to Bangkok have considerably lower fertility.

A major advantage of using place of residence five years preceding the census to determine migration status lies in the shorter time during which geographic mobility could occur, although it still does not permit exact determination of when children were born in relation to the migration. However, for younger migrant women, in particular, the chances are greater that the move preceded at least a portion of their child bearing; 
fertility differentials among younger women therefore take on particular significance for five-year migrants.

The five-year migration data indicate a pattern quite different from that characterizing the lifetime statistics. For the total kingdom, the age standardized fertility level of migrant women is $10.4 \mathrm{per}$ cent below that of the non-migrants. Moreover, the differential persists for all urban-rural categories. It is narrowest for the rural, agricultural group (5 per cent) and widest for the urban categories, with Bangkok's average for migrant women being 13 per cent below that of the non-migrants.

With age controlled (for detailed data see Goldstein, 1971a), the five-year migration data indicate that only for recent migrants under age $\mathbf{4 0}$ in Bangkok were the fertility levels well below those of the non-migrant women. Fertility levels of older, recent migrants, who presumably bore all or most of their children before migration, were quite similar to those of the non-migrants. Again, comparison of the fertility levels of the Bangkok migrants with those of the non-migrant women in rural places showed that at all ages Bangkok migrants displayed fertility levels far below those of the rural, agricultural women.

Overall, then, these two sets of migration data for Thailand, based on the 1960 Census, lend support to the conclusion that the fertility levels of migrants did not exceed those of non-migrants. In fact, for recent migrants they were below those of the non-migrating population in place of destination. This finding may reflect the selection of women with lower average number of children at place of origin and/or lower fertility in the years immediately following settlement in the place of destination, possibly as the result of obstructing factors, social or physiological, associated with the migration process. It may also reflect the lesser likelihood that women who are pregnant or have small children will migrate. The differential for recent migrants characterized all urban-rural categories, suggesting that it operated independently of place of destination. At the same time, the fact that the fertility of migrants, like that of the non-migrants, had a direct relation to urban-rural residence suggests that place of destination influences the selective process, so that either urban places attract women with much lower fertility levels or migrants fairly rapidly assimilate the general pattern of lower fertility behaviour in the place of destination.

\section{Changes in Fertility, 1960-1970}

The 1970 Census provides the first opportunity to undertake a comparison of fertility levels for Thailand based on two successive censuses. Obviously, there are serious limitations in doing so, even though the same measure of fertility - children ever born - is used. Social and economic development during the 1960-70 interval, improvements in census-taking procedures, and limitations inherent in this particular measure of fertility could all affect the comparability of the two sets of data.

According to the 1970 Census, the 4,692 children born per 1,000 ever-married women in the kingdom was higher that the 4,316 average for 1960 , when age is standardized. ${ }^{1}$ But for the reasons suggested earlier, caution must be exercised before concluding from these data that fertility actually increased in Thailand during the 1960s. Assessment elsewhere (Chamratrithirong, 1976) suggests that the fertility rise observed between 1960 and 1970, based on the published data on children ever born, is actually an artifact of data collection and processing procedures related to age of mother. The lack of direct comparability between the available 1960 and 1970 data thus suggests that the more meaningful comparisons are those among the various segments of the population covered in a given census year, among whom more comparable procedures operated. This 
Sidney Goldstein

TABLE 2. NUMBER OF CHILDREN EVER BORN PER 1,000

EVER-MARRIED WOMEN BY LIFETIME AND FIVE-YEAR INTERPROVINCIAL MIGRATION STATUS, BY CURRENT PLACE OF RESIDENCE, 1970

(Standardized for Age)

\begin{tabular}{|c|c|c|c|c|c|}
\hline \multirow[b]{2}{*}{ Residence } & & \multicolumn{2}{|c|}{$\begin{array}{l}\text { Ever Married Women } \\
\text { Aged } 15 \text { and Over }\end{array}$} & \multicolumn{2}{|c|}{$\begin{array}{l}\text { Ever Married Women } \\
\text { Age } 15-44\end{array}$} \\
\hline & & $\begin{array}{l}\text { Non- } \\
\text { migrants }\end{array}$ & Migrants & $\begin{array}{c}\text { Non- } \\
\text { migrants }\end{array}$ & Migrants \\
\hline \multicolumn{6}{|c|}{ LIFETTME MIGRATION STATUS ${ }^{1}$} \\
\hline $\begin{array}{l}\text { Bangkok } \\
\text { Provincial Urban } \\
\text { Rura1 }\end{array}$ & Places & $\begin{array}{l}3,730 \\
4,149 \\
4,827\end{array}$ & $\begin{array}{l}3,557 \\
3,976 \\
5,029\end{array}$ & $\begin{array}{l}3,142 \\
3,571 \\
4,105\end{array}$ & $\begin{array}{l}3,024 \\
3,402 \\
4,182\end{array}$ \\
\hline Total Kingdom & & 4,761 & 4,635 & 4,047 & 3,841 \\
\hline \multicolumn{6}{|c|}{ FIVE-YEAR INTERPROVINCIAL MIGRATION STATUS 2} \\
\hline $\begin{array}{l}\text { Bangkok } \\
\text { Provincial Urban } \\
\text { Rural }\end{array}$ & Places & $\begin{array}{l}3,688 \\
4,145 \\
4,858\end{array}$ & $\begin{array}{l}3,406 \\
3,690 \\
4,748\end{array}$ & $\begin{array}{r}3,136 \\
3,576 \\
4,124\end{array}$ & $\begin{array}{l}2,851 \\
3,101 \\
3,934\end{array}$ \\
\hline Total Kingdom & & 4,757 & 4,433 & 4,035 & 3,668 \\
\hline
\end{tabular}

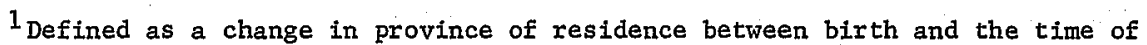
the Census.

2 Defined in terms of a different province of residence in 1970 from the province of residence in 1965.

Source: 1970 Thai Census.

limitation is not serious here, however, since the major focus of this research is not so much on changing fertility patterns over time as on the variations in fertility among women of different migration statuses and between urban and rural fertility levels among both migrants and non-migrants.

As in 1960, in 1970 the extent of difference between the fertility of migrants and non-migrants varied, depending on the particular definition of migrants used (Table 2). Among those women classified as lifetime migrants, the 4,635 average number of children born, with age standardized, was only 2.6 per cent below the average of the non-migrant women. The average number of children ever born to five-year interprovincial migrants $(4,433)$ was lower than the average born to both non-migrants and lifetime migrants. As for 1960 , therefore, these data for the total kingdom suggest that only recent migration has a noticeable effect on fertility level; it tends to lower it, but the extent of the differential is only about 10 per cent and actually narrowed between 1960 and 1970 . Since many of the children, particularly those of the older women, were born before the recent migration occurred, the average for specific ages and particularly for the younger women may be more relevant.

The greater differences generally characterize younger women, who are at earlier stages of child bearing and, therefore, who likely have had fewer children before migration than have the older women. This pattern suggests that factors directly associated with the migration process contribute most to lowering the fertility of migrants. The smaller differences characterizing older women and the still smaller ones of the lifetime migrants are consistent with such an interpretation. The differences could also reflect changes in the selection of migrants. 
Because of the urban-rural differentials in fertility, it is essential to assess the relation of migration and fertility for the various residential categories. By 1970, the basic pattern for lifetime migrants had changed only slightly from what it had been in 1960. Minimum differences continued to characterize Bangkok and provincial urban places, and in rural places migrants continued to have higher fertility than non-migrants. Overall, these comparisons suggest that the same underlying causes that were operating in 1960 to ar cunt for the small differences in fertility between lifetime migrants and non-migrants in urban and rural places persisted into 1970.

The data for five-year migrants yield a somewhat different pattern than the lifetime statistics. In 1960, migrants had lower fertility than non-migrants in all three residential categories, but the greatest difference characterized Bangkok and the smallest difference characterized rural places. The same direction of difference characterizes all three residential categories in 1970, but the magnitude of the difference between migrants and non-migrants is somewhat less for Bangkok and for rural locations than in 1960 and slightly greater for the provincial urban places. Even if the analysis is restricted to those women still in their child-bearing years (thereby precluding any distortion introduced by inclusion of women aged 45 and over among five-year migrants), the same pattern emerges, except that the differences are approximately 2 per cent greater for each residential category, suggesting somewhat wider differences between younger migrants and non-migrants. Again, the key point is that the differences for the five-year migrants are greater than those for the lifetime migrants. The fact that in 1970 this was more characteristic of provincial urban places and less so of Bangkok than it was in 1960 suggests that the character of migration to these locations has changed in the 10-year interval - that migration to Bangkok may be less selective of women with low fertility than was true formerly and that migration to the provincial urban places has become more selective. The narrow difference between the rural migrants and non-migrants, once age is controlled, suggests, as did the pattern for lifetime differentials, that the relation between migration and fertility in rural areas is different from that which characterizes movement to cities.

As in 1960, the urban-rural differentials are far greater than the differentials between migrants and non-migrants. Using either the lifetime or the five-year migration definition, the average number of children born to both non-migrants and migrants in Bangkok was about one-fourth lower than that of the respective non-migrant and migrant women in rural places. These differentials suggest the significant implications that increasing levels of urbanization may have for changing levels of fertility in the total kingdom.

At the same time, as noted in the 1960 analysis, these urban-rural differentials raise new questions about the selective character of the migration process. Since a substantial proportion of the migrants, regardless of place of residence in 1970, were of rural origin, and since rural fertility levels are considerably higher than urban ones, migrants to urban places, especially to Bangkok, might be expected to have higher fertility than the non-migrant women in the place of destination. Yet this was not true; selection was operating, either at the point of origin or in the fertility adjustment to migration. To gain further insights with respect to factors that were, in fact, operating, it is necessary to turn to the data on migration streams. Before doing so, however, advantage will be taken of the opportunity afforded by the 1970 Census to explore the relation between urban/rural migration and fertility using a more refined measure of migration. 
Five-Year Urban/Rural Migration and Fertility, 1970

The foregoing assessment classified lifetime and five-year migrants in terms of movement between different provinces. This definition of migration was used in order to provide comparability of data for both the 1960 and 1970 Censuses. It thus excluded from the migrant category all those women who had changed residence in the specified interval between one location and another within the same province - that is, women who had moved between villages, between municipal areas, or between a village and a municipal area in either direction, while remaining within the same province. For an analysis of the relations among migration, fertility, and urbanization, it is particularly important to take all rural and urban changes of residence into account, regardless of the distance of the move. Greater adjustments may be required in a short distance move between two different types of communities, especially between a rural and an urban location, than is the case in a long-distance move between similar types of locations; a village-to-village or urban-to-urban change over a long distance may be undertaken much more easily than a rural-urban move within the same province.

Information on intraprovincial moves was available from the 1970 Census. Furthermore, all persons who had moved within the five years preceding the census were asked whether the place of origin of the move was a village or a municipal area. For persons who had made more than one move in the five-year interval, information was obtained only on the last move. These data are used in the later analysis of the extent to which fertility levels vary depending on different combinations of rural-urban origin and destination. First, however, attention must be given to the effect of the expanded migration classification, first on the number of ever-married women who qualify as migrants and second on the levels of migrant and non-migrant fertility.

Changes in the definition of migration obviously affect the proportion of ever-married women who are classified as migrants. In 1970, for the kingdom as a whole, 16 per cent of the ever-married women were classified as lifetime migrants, and 5 per cent as interprovincial, five-year migrants. Under each definition, Bangkok had the highest proportion of migrant women (57 per cent were lifetime migrants, 14 per cent five-year migrants) and rural places the lowest percentage (13 and 4 per cent, respectively, were lifetime and five-year migrants).

Inclusion of the urban/rural intraprovincial migrants in the migrant category doubles the proportion of married women who are five-year migrants, to 11 per cent, although the increase is smallest for Bangkok and largest for rural areas. In general, it produces only minor changes in the extent of fertility differentials between five-year migrants and non-migrants. As under the more restricted definition of migration, wider differentials characterize the fertility levels of migrants and non-migrants in Bangkok and in provincial urban places compared to the levels in rural places. This pattern extends to virtually all age groups but is particularly characteristic of women still in their reproductive years, among whom the differentials are generally wider than for the population as a whole. If only the fertility levels of women aged 15 to 44 are considered to reflect the experience of those women whose recent fertility is more closely related to the time of migration - the differences are somewhat greater than for all women. Such a change suggests that when migration occurs during the active period of the reproductive cycle, it is more likely to affect fertility (Table 3 ).

Although the data clearly point to differential fertility between migrants and non-migrants in both urban areas and rural places, the differences were not particularly great. More important, both migrant and non-migrant groups were characterized by wide differences in the number of children ever born to women living in Bangkok compared to those living in rural areas. Among non-migrants, Bangkok women averaged 24 per cent 
TABLE 3. NUMBER OF CHILDREN EVER BORN PER 1,000 EVER-MARRIED WOMEN BY FIVE-YEAR URBAN/RURAL MIGRATION STATUS,**BY CURRENT AGE AND PLACE OF RESIDENCE, 1970

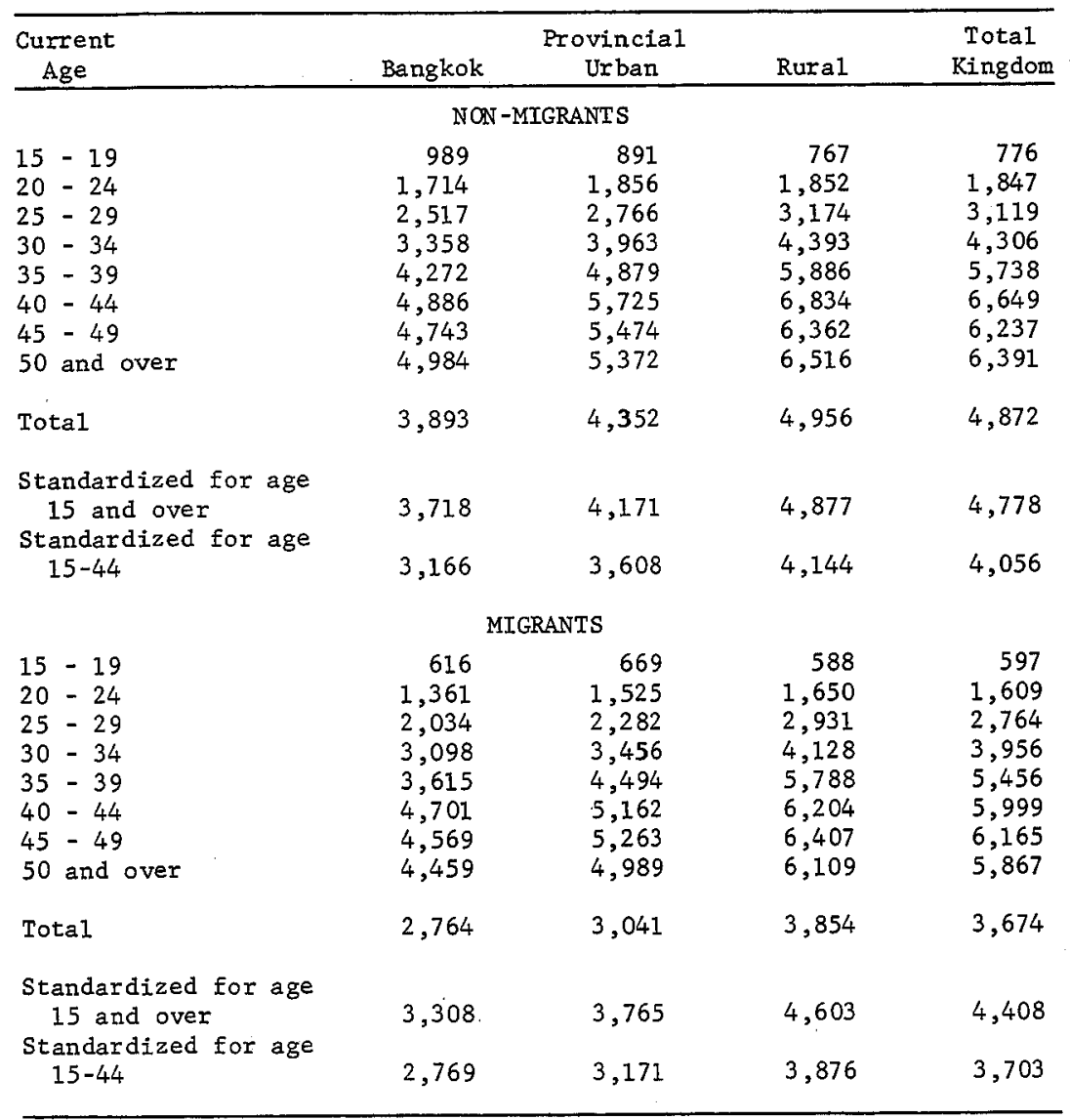

* Defined as a change in village or municipal area of residence between 1965 and 1970, including both inter- and intraprovincial moves.

Source: 1970 Thai Census.

fewer children than did the rural non-migrant women; among migrants, the average number of children ever born to Bangkok women was 28 per cent below that for rural women. For the age-specific data, too, the sharper differentials characterize the residence categories rather than the migrant/non-migrant comparisons, pointing to the important impact of urban residence on fertility levels.

\section{Fertility Levels by Origin and Destination}

Because the 1970 Census statistics include information on the urban and rural character of both the place of origin and the place of destination, they provide an opportunity for comparing the fertility levels of different migration streams. ${ }^{2}$ These data refer to women classified as migrants or non-migrants according to the urban/rural definition of migration, which encompasses both the inter- and intraprovincial movement. 
Sidney Goldstein

The proportions of migrants from rural and urban origins were quite different for migrants to Bangkok and to provincial urban places and between these two urban categories and rural locations. Over half (54 per cent) of the recent migrants to Bangkok came from urban places compared to 43 per cent of those who moved to smaller urban places. For both residential categories, therefore, these data testify to the significant amount of urban to urban interchange that characterizes recent movement within Thailand. By contrast, over 90 per cent of the movement reported by 1970 rural residents is from other rural places. Yet, 8 per cent of all five-year migrants in rural places came from urban locations, suggesting that movement is not uni-directional and that urban to rural movement is of sufficient magnitude to merit attention. In absolute terms, in fact, the number of such migrants $-41,000$ - accounts for 43 per cent of all urban-origin movement and is equal in volume to 69 per cent of the movement to urban locations from rural places. Only when related to the large absolute size of the rural-to-rural movement and to the rural population itself does it become relatively small.

For the total kingdom, migrants who moved from rural places during 1965-70 had a higher fertility level $(4,618)$ than did the urban-origin migrants $(3,675)$ (Table 4$)$. This large differential is misleading, however, since such a high percentage of the rural-origin migrants also had a rural location as their destination. In large measure, therefore, the differences parallel those that characterize the non-migrants in the rural and urban locations. Yet the fertility of the migrants was below that of the non-migrants in the respective places of origin, again indicating that for five-year migrants the migration process is associated with lower fertility at point of origin, paralleling the lower fertility that also exists at point of destination. The lower fertility of the migrants is characteristic of rural-origin women in every age group below age 45 and of every age group of urban-origin women.

Most relevant to the present analysis are the fertility levels of the specific migration streams. For both those of rural origin and those of urban origin, the average number of children ever born varies inversely with 1970 residence on the urban-rural continuum. Among the migrants who originated in rural places, the average number of children ever born per 1,000 women, with age standardized, increased from 3,522 for those who moved to Bangkok to 3,852 for those who moved to smaller urban places and then jumps to a high of 4,701 among those changing residence from one rural village to another. Clearly, the type of destination of the rural-origin move is associated with fertility level.

Among the migrants originating in urban locations, the averages also change in relation to the type of destination, from 3,306 among those moving to Bangkok to 3,691 for those going to provincial urban places, reaching a slightly higher average, 3,818 , for those migrating from an urban to a rural location. Thus, although arban-origin women moving to Bangkok have a lower average number of children ever born than those moving to a rural destination, the range of difference is well below that characterizing the rural-origin group, suggesting the influence that urban origin may have in lowering fertility, even on the part of those moving to a rural location. The particularly high fertility level of migrants between rural locations marks them as a distinctive group.

In every instance, if comparisons are made within particular destination categories, the average number of children born to the rural-origin migrants is higher than that characterizing the urban-origin group, but the difference is only substantial between the two migration streams whose destinations are rural. For women 15 and over, the differential between those moving from rural to rural locations in comparison to those coming from an urban to a rural place is almost five times greater than the difference between the rural- and urban-origin migrants moving to Bangkok.

The observed pattern of differentials within the rural-origin group extends to all the 
TABLE 4. AVERAGE NUMBER OF CHILDREN EVER BORN PER 1,000 EVER-MARRIED WOMEN BY URBAN/RURAL PLACE OF ORIGIN AND DESTINATION, BY CURRENT AGE, 1970

\begin{tabular}{|c|c|c|c|c|c|}
\hline \multirow{2}{*}{$\begin{array}{l}\text { Current } \\
\text { Age } \\
\end{array}$} & \multicolumn{3}{|c|}{ Place of Destination* } & \multirow{2}{*}{$\begin{array}{c}\text { Total } \\
\text { Migrants }\end{array}$} & \multirow{2}{*}{$\begin{array}{c}\text { Non- } \\
\text { Migrants }\end{array}$} \\
\hline & & ovincia & & & \\
\hline & \multicolumn{3}{|c|}{ RURAI ORIGIN } & & RURAL \\
\hline $\begin{array}{l}15-19 \\
20-24 \\
25-29 \\
30-34 \\
35-39 \\
40-44 \\
45-49 \\
50 \text { and over }\end{array}$ & $\begin{array}{r}471 \\
1,294 \\
2,030 \\
3,077 \\
3,989 \\
4,925 \\
4,927 \\
5,001\end{array}$ & $\begin{array}{r}621 \\
1,515 \\
2,335 \\
3,518 \\
4,525 \\
5,456 \\
5,870 \\
4,953\end{array}$ & $\begin{array}{l}602 \\
1,666 \\
2,919 \\
4,197 \\
5,903 \\
6,649 \\
6,617 \\
6,136\end{array}$ & $\begin{array}{r}597 \\
1,635 \\
2,832 \\
4,105 \\
5,759 \\
6,528 \\
6,537 \\
6,021\end{array}$ & $\begin{array}{r}767 \\
1,852 \\
3,174 \\
4,393 \\
5,886 \\
6,834 \\
6,362 \\
6,516\end{array}$ \\
\hline Total & 2,546 & 3,041 & 3,834 & 3,724 & 4,956 \\
\hline \multirow{3}{*}{$\begin{array}{l}\text { Standardized for age } \\
15 \text { and over } \\
\text { Standardized for age } \\
\quad 15-44\end{array}$} & 3,522 & 3,852 & 4,701 & 4,618 & 4,877 \\
\hline & 2,852 & 3,239 & 3,985 & 3,913 & 4,144 \\
\hline & \multicolumn{3}{|c|}{ URBAN ORIGIN } & & URBAN \\
\hline $\begin{array}{l}15-19 \\
20-24 \\
25-29 \\
30-34 \\
35-39 \\
40-44 \\
45-49 \\
50 \text { and over }\end{array}$ & $\begin{array}{r}765 \\
1,331 \\
2,043 \\
3,070 \\
3,634 \\
4,966 \\
4,456 \\
4,338\end{array}$ & $\begin{array}{r}784 \\
1,543 \\
2,178 \\
3,401 \\
4,364 \\
4,897 \\
4,894 \\
5,056\end{array}$ & $\begin{array}{r}407 \\
1,397 \\
2,874 \\
3,512 \\
4,749 \\
4,033 \\
5,524 \\
5,227\end{array}$ & $\begin{array}{r}634 \\
1,415 \\
2,409 \\
3,348 \\
4,340 \\
4,440 \\
5,053 \\
4,867\end{array}$ & $\begin{array}{l}925 \\
1,786 \\
2,640 \\
3,632 \\
4,552 \\
5,291 \\
5,113 \\
5,188\end{array}$ \\
\hline Total & 2,810 & 3,075 & 3,433 & 3,145 & 4,120 \\
\hline $\begin{array}{l}\text { Standardized for age } \\
15 \text { and over } \\
\text { Standardized for age }\end{array}$ & 3,306 & 3,691 & 3,818 & 3,675 & 3,938 \\
\hline $15-44$ & 2,818 & 3,083 & 3,136 & 3,105 & 3,373 \\
\hline
\end{tabular}

*Equivalent to place of residence in 1970.

Source: 1970 Thai Census.

age subcategories; in every instance the average number of children born to Bangkok-destined migrants is below that of the rural-to-rural migrants. Those who take up residence in provincial urban places fall either intermediary or, in the case of the youngest and the oldest groups, are equal to one of the other categories. With only a few exceptions, the same pattern of differentials extends to the age groups of the urban-origin women. The same pattern is also generally characteristic of women still in their reproductive years (aged 15 to 44 ) taken as a whole.

Overall, therefore, these data suggest that urban destination, more than the nature of the urban or rural origin of migrants, distinguishes the fertility levels of migrants. At the same time, the much closer similarity in the fertility levels of urban-origin groups, regardless of destination, indicates that prior urban residence is associated with lower fertility among migrants regardless of the place of destination of the move. Yet the fact 
that the lowest fertility is displayed by the urban migrants to Bangkok and the highest by the rural migrants to other rural locations suggests, in turn, that the interaction of factors associated with origin and destination have an important joint impact on fertility levels. For all women, with age standarized, the average of 3,306 for urban-origin migrants to Bangkok was far below the 4,701 average characterizing rural-to-rural migrants. For women still in their reproductive years, the 2,818 average for urban-to-Bangkok migrants remained well below the 3,986 average of the rural-to-rural migrants. Furthermore, these extreme averages, especially for urban-origin migrants to Bangkok, were still below the averages characterizing the non-migrants in the respective places of origin and destination, suggesting that factors associated with both the selection and the adjustment of migrants have an impact on fertility levels.

Of particular interest is the low fertility of urban-to-rural migrant women. It is well below the fertility of those moving from one rural place to another and even slightly below that of rural to provincial urban migrants. This pattern is indicative both of the impact of place of origin on the fertility of these urban-to-rural movers and of their potential role, despite their small numbers in the total rural population, as "models" of low fertility in the rural location into which they move.

\section{Discussion}

The foregoing analysis has demonstrated the complexity of the interrelations between migration and fertility. Almost no differences exist between the fertility levels of lifetime migrants and those of non-migrants at destination, but the fertility of five-year migrants is below that of non-migrants at both destination and origin, and the lowest fertility characterizes women moving to Bangkok. These findings are corroborated by evidence from the Longitudinal Study of Social, Economic, and Demographic Change in Thailand, conducted in 1969 and 1970 (Goldstein and Tirasawat, 1977).

These different patterns suggest several possible relations. The migration process (especially rural-to-urban migration) may be disruptive of fertility, but its effects may dissipate with longer periods of residence in the place of destination. Several factors may help to explain the disruptive character of the migration process. The move itself may be sufficiently disturbing from a socio-psychological perspective as to actually interfere with the physiological capacity to conceive and bear children. Migration may also often involve an initial period of separation between spouses, a period which constituted a larger portion of the total stay of recent than earlier migrants, thus reducing the fertility of the recent migrants (cf. Visaria, 1969; Borrie and Cameron, 1969:72).

Another factor in the lower fertility of recent migrants relates to the fact that a considerable part of female migration to the city may have been to obtain employment. Reflecting this, recent female migrants participate in the labour force to a greater extent than does the rest of the female population, and this, too, is likely to contribute to lower fertility (S. Goldstein, A. Goldstein, and Tirasawat, 1972). Moreover, women arriving in cities in recent years have had easier access to family planning information and clinics than had earlier arrivals (Visaria, 1969).

An alternative explanation, using Petersen's typology (Petersen, 1975:317-326), is that more recent migration in Thailand may be more innovative in character than earlier migration, which was more conservative. The earlier migrants may have responded to changes in their environment by conforming more closely to older behaviour patterns, including maintenance of somewhat higher fertility levels. By contrast, more recent migrants, motivated by improved communication, more education, and higher levels of modernization may be leaving their old environments in order to achieve new goals. 
Therefore, they may be more willing to forego the old in favour of new behaviour patterns, including fertility that is lower not only than that of couples at place of origin but also in comparison to non-migrants and to long-term migrants $>$ in place of destination. Further testing of this hypothesis is needed through assessment of whether the differential pattern of fertility levels of recent young migrants changes after additional years of residence in the places of destination.

Yet, overriding the differences by migration status are the urban-rural fertility differentials and those between Bangkok and provincial urban places. These differentials are generally even greater than those between the migrants and non-migrants and persist even after migration status is controlled. Clearly, urbanization is associated with lower fertility among both migrants and non-migrants. The fact that there are differences even between Bangkok and smaller urban places stresses the special impact that the "more" urban place has on fertility, either directly or by the greater attraction of women with lower fertility. It becomes important, therefore, to identify those aspects of urbanization that contribute to lower fertility and that may be introduced or enhanced in smaller urban places and especially in rural areas as part of efforts to reduce fertility in these locations. Exploitation of the census data on the social, economic, and demographic characteristics of the migrants will allow this in later analyses.

The present data also suggest that the continuing high fertility levels in rural areas may reflect, in small part, the net effects of selective migration; that is, the more traditional population - persons tending to have higher fertility - remains behind in rural areas. This assumes that the fertility level of the migrants, had they remained in rural areas, would have been lower than that of the stable elements in the population. If this assumption is correct, the fertility level of the rural population may, in fact, become higher still if reduced pressure on the land resulting from out-migration or from greater economic opportunities for the use of manpower, possibly in conjunction with the Green Revolution, places a premium on children. In turn, such higher fertility may create, especially during rural crisis situations, added pressures for rural-to-urban migration.

If, as a result of the general effort to develop rural areas and the more specific efforts to introduce family planning there, fertility control becomes widespread in rural areas of Thailand, the fertility differentials between rural and urban women will likely narrow, and the selection process of rural-to-urban migration with regard to fertility may change. Eventually, with more widespread introduction of "urban ways" into rural settings, selective out-migration may taper off, and fertility differentials between migrants and non-migrants at origin as well as at destination may diminish.

\section{Acknowledgment}

The research was conducted pursuant to Contract No. NIH 70-2190 with the National Institutes of Health, Department of Health, Education, and Welfare. The co-operation of the National Statistical Office of Thailand, and especially Mrs. Anuree Wangli, in making the:1970 Census sample tape data available is gratefully acknowledged.

This paper is a version of one presented at the Commission on Population Geography Symposium of the International Geographical Union held in Minsk, USSR, 21-26 July 1976.

Footnotes

1. To insure comparability with the data from the 1960 Census, foreign-born women are included in this analysis comparing 1960 and 1970 fertility differentials. Later analyses, using only the 1970 Census, will be restricted to native-born women since the focus of this research is on interrelations between internal migration and fertility.

2. No information was obtained on urban-rural origin for 11 per cent of all migrant, ever-married women. The reason for this comparatively high lack of response is not clear; it may reflect the novelty of the question and 
the difficulties faced by respondents and/or interviewers in ascertaining the rural-urban character of the previous place of residence. The problem is not unique to Thailand. In the United States 1970 Census, 11 per cent of all movers were reported with 1965 residence not determined.

For Thailand, the extent of no information on urban-rural origin of move varied by 1970 residence. Just under 10 per cent of the ever-married women migrants to rural and provincial urban places but almost one in four of the migrants to Bangkok are classified as rural-urban origin unknown. Bangkok may have a higher proportion of unknowns because many more ever-married women may have been absent from home at the time of the interview and, therefore, did not answer the census question themselves, but this remains speculative. For all three locations, but especially for Bangkok, level of non-reporting of origin varies directly with age. For the capital, only 12 per cent of the women aged 15 to 19 and 16 per cent of those aged 20 to 24 , but 29 per cent or more of those in age groups 35 and over were in the unknown group. To the extent that those with younger children were more likely to be home, this pattern supports the earlier speculation on the reason for the high non-response in Bangkok. In both provincial urban places and rural areas, the percentages rarely exceeded 10 per cent for all but the 40 and over age groups.

In the analysis of the interrelations between fertility and migration, women of unknown origin are omitted. Overall, the average number of children born to this group, with age standardized, is 4.1 per woman. This compares with 4.6 for the rural-origin and 3.6 for the urban-origin migrants, suggesting that the composition of the group represents a mix of rural- and urban-origin women. Omission of this group needs to be kept in mind. It also affects comparisons with statistics that do not include attention to origin, since women of unknown rural-urban origin are included in the total migrant categories.

\section{References}

Arnold, Fred, and Supani Boonpratuang. 1976. 1970 Population and Housing Census: Migration. Subject Report 2. Bangkok: National Statistical Office.

Borrie, W.D., and Morag Cameron, Eds. 1969. Population Change: Asia and Oceania. Canberra, Australia: Department of Demography, Australian National University.

Chamratrithirong, Apichat: 1976. Fertility, Nuptiality, and Migration in Thailand, 1970 Census: The Multiphasic Response Theory. Unpublished Ph.D. dissertation. Providence, R.I.: Brown University.

Goldstein, Sidney. 1970 Religious Fertility Differentials in Thailand. Population Studies 24:324-337. . 1971a. Interrelations between Migration and Fertility in Population Redistribution in Thailand. Research Report 5. Bangkok: Institute of Population Studies, Chulalongkorn University.

1971b. Urbanization in Thailand, 1947-1967. Demography 8:205-223.

. 1972. The Demography of Bangkok: A Case Study of Differentials between Big City and Rural Populations. Research Report 7. Bangkok: Institute of Population Studies, Chulalongkorn University.

Alice Goldstein, and Penporn Tirasawat. 1972. The Influence of Labor Force Participation and Education on Fertility in Thailand. Research Report 9. Bangkok: Institute of Population Studies, Chulalongkorn University.

, and David Sly, Eds. 1975. Basic Data Needed for the Study of Urbanization. Working Paper 1. Liege: International Union for the Scientific Study of Population.

, and Penporn Tirasawat. 1977. The Fertility of Migrants to Urban Places in Thailand. Paper 43. Honolulu, Hawaii: East-West Population Institute, East-West Center.

Petersen, William. 1975. Population. 3rd edition. New York: The MacMillan Company.

Visaria, Pravin M. 1969. Urbanization, Migration, and Fertility in India. In The Family in Transition. Fogarty International Center Proceeding 3:257-283. Washington, D.C.: Government Printing Office.

Zarate, Alvan, and Alicia Unger de Zarate. 1975. On the Reconciliation of Research Findings of Migrant-Nonmigrant Fertility Differentials in Urban Areas. International Migration Review. 9:115-156.

Received October, 1977; Revised July, 1978 